\title{
The members' enquiry service: frequently asked questions September 2002-August 2003 and an illustrative CEU response
}

\author{
Alison de Souza, MPH, Research Assistant; Susan Brechin, MRCOG, MFFP, Unit Co-ordinator; Gillian Penney, FRCOG, MFFP, \\ Honorary Director, Clinical Effectiveness Unit, Faculty of Family Planning and Reproductive Health Care, London, UK
}

Correspondence: MS A de Souza; FFP CEU, Office 63, Aberdeen Maternity Hospital, Cornhill Road, Aberdeen AB25 2ZD, UK. Tel+44 (0) 1224 553623. E-mail: ffp.ceu@abdn.ac.uk

(Accepted 6 February 2004)

Journal of Family Planning and Reproductive Health Care 2004; 30(2): 111-113

\section{Introduction}

In this article, the Clinical Effectiveness Unit (CEU) provides an overview of the enquiries received in their first year of operation, from September 2002 to August 2003. An illustrative response to one frequently asked question (FAQ), namely the use of progestogen-only emergency contraception (POEC) by women taking liver enzymeinducers, is given at the end of this overview. All CEU enquiry responses will soon be accessible via a searchable facility on the Faculty of Family Planning and Reproductive Health Care (FFPRHC) website.

By the end of August 2003 the CEU had responded to 300 enquiries. The majority $(70 \%)$ of these were received by e-mail, $19 \%$ by telephone, $10 \%$ by post and $1 \%$ by fax. Figure 1 summarises the topic areas covered by these enquiries.

The largest category of enquiries, 'all methods' (60 enquiries), included questions about contraceptive choices for women with specific clinical conditions or syndromes.

The 'intrauterine devices' category included questions on protocols for insertion and removal, efficacy of different devices, and the suitability of this method for women with specific clinical conditions. Questions on testing for Chlamydia trachomatis prior to insertion and on the relevance of actinomyces-like organisms on cervical smears of intrauterine contraceptive device users were answered individually and have also been addressed in the CEU Guidance document 'The copper intrauterine device as long-term contraception'. 1

Within the 'combined pills' category, clinicians sought advice on the risks of venous thromboembolism and breast

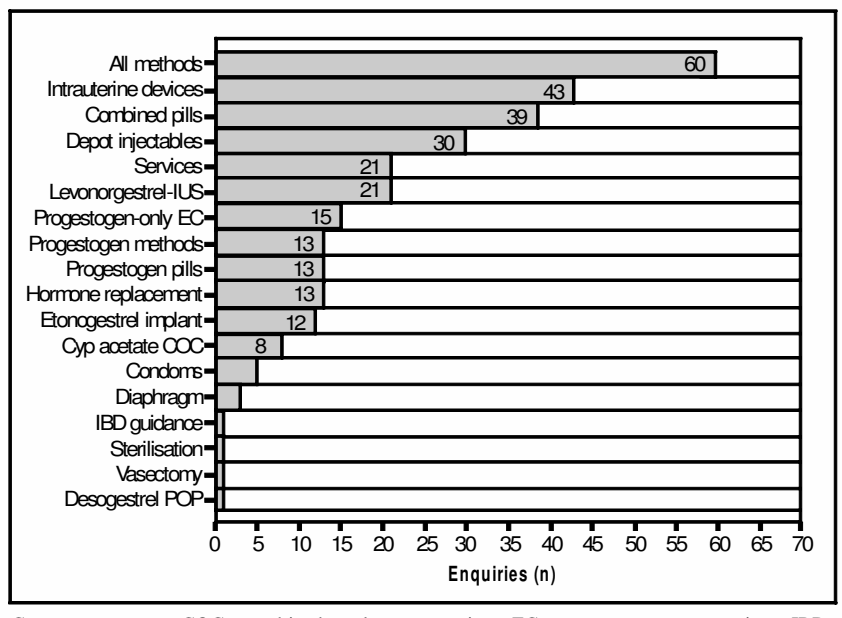

Cyp, cyproterone; COC, combined oral contraceptive; EC, emergency contraception; IBD, inflammatory bowel disease: IUS intrauterine system; POP, progestogen-only pill.

Figure 1 Topic areas of members' enquiries during the period September 2002-August 2003 cancer, on different doses of combined oral contraception, and on drug interactions. A common enquiry topic was combined contraceptive use by women taking antiepileptic liver enzyme-inducers. This topic was covered in a previously published illustrative response. ${ }^{2}$

The two most common topics within the 'depot injectables' category related to 'late injections' and to the effects of long-term use on bone mineral density. Our responses on late depot medroxyprogesterone acetate (DMPA) injections were based on guidance in the World Health Organization (WHO) Selected Practice Recommendations for Contraceptive Use. ${ }^{3}$ A response on the effects of DMPA on bone mineral density has been published as an illustrative FAQ. ${ }^{4}$

Within the 'services' category, members asked for guidance on cervical smears, including the role of the pelvic examination, and accuracy of different screening techniques. Fifteen enquiries related to 'progestogen-only emergency contraception'. The new, approved regimen of a single $1.5 \mathrm{mg}$ dose taken within 72 hours of unprotected sexual intercourse featured in many responses and in our formal CEU Guidance on 'Emergency contraception'.5 Several members were unsure about the application of this new regimen for women using liver enzyme-inducers. To clarify this issue, the CEU provides a response to this FAQ here. Enquiry topics on the 'etonogestrel implant' included duration of use in women with a high body mass index.

The CEU answered multiple enquiries on the following topics: the relationship between hormone replacement therapy and breast cancer; the reliability of gonadotrophin measurements in diagnosis of the menopause; the risk of venous thromboembolism with all forms of progestogenonly contraceptives and with pills containing cyproterone acetate; the risks of the spermicide, nonoxynol-9; and efficacy of the progestogen-only pill in women weighing $>70 \mathrm{~kg}$. The CEU has published a response to this latter FAQ. ${ }^{6}$ Isolated enquiries were received on the CEU Guidance document 'Contraceptive choices for women with inflammatory bowel disease', ${ }^{7}$ on the efficacy of new contraceptive products such as the desogestrel-only pill, and on sterilisation and vasectomy.

The CEU also received 43 miscellaneous queries, which are not included in this summary of the members' enquiry service. These included requests for information on ongoing clinical trials, new product details, audit standards, medicolegal advice, and access to CEU publications or presentations.

Table 1 summarises the 10 most common topic areas of questions asked during the CEU's first year in operation. The CEU has provided answers to most of these FAQs in previous illustrative responses or in their Guidance documents. 
Table 1 The 10 most common themes of members' enquiries during the period September 2002-August 2003

1 The use of combined oral contraception by women taking anti-epileptic liver enzyme-inducers.

2 Guidance on late depot medroxyprogesterone acetate (DMPA) injections.

3 The effects of long-term DMPA use on bone mineral density.

4 The risk of vaginal ulceration and sexually transmitted infections with condoms lubricated with nonoxynol-9.

5 Efficacy of the single $1.5 \mathrm{mg}$ dose of progestogen-only emergency contraception for women taking liver enzyme-inducers.

6 Follow-up of women using different contraceptives.

7 Testing for Chlamydia trachomatis prior to intrauterine device (IUD) insertion.

8 Relevance of actinomyces-like organisms on cervical smears of women with IUDs or prior to IUD insertion.

9 The risks of venous thromboembolism (VTE) in women using progestogen-only contraception.

10 The risk of VTE in women using pills containing cyproterone acetate.

\section{Illustrative CEU response}

Clinical question

For women taking liver enzyme-inducers, what dose of POEC is effective?

\section{Summary of response}

The CEU recommends that, in routine practice, POEC can be administered as two tablets taken together $(1.5 \mathrm{mg}$ levonorgestrel), which should be taken as soon as possible, and within 72 hours of unprotected sex or potential contraceptive failure. There is no evidence available regarding use of POEC in women using liver enzymeinducers; currently, a consensus opinion is that such women should take one additional tablet $(0.75 \mathrm{mg}$ levonorgestrel) 12 hours later.

\section{Evidence-based medicine question (which guided our \\ literature search strategy)}

Population: Women taking liver enzyme-inducers.

Intervention: Progestogen-only emergency contraception.

Outcome: Efficacy of the regimen.

\section{Information sources}

The CEU searched the sources listed in Table 2 in developing this Member's Enquiry Response.

\section{Evidence reviewed}

Existing FFRPHC Guidance. The CEU Guidance on 'Emergency contraception' (April 2003) ${ }^{5}$ updated previous Faculty Guidance. ${ }^{8}$ The dose of POEC should be increased by $50 \%$ for women using liver enzyme-inducers. ${ }^{9}$ Alternatively women should consider using a copper

Table 2 Sources used in developing the Member's Enquiry Response

\begin{tabular}{ll}
\hline Source searched & $\begin{array}{l}\text { Information } \\
\text { identified }\end{array}$ \\
\hline $\begin{array}{l}\text { Existing FFPRHC and RCOG Guidance } \\
\text { The National Guidelines Clearing House }\end{array}$ & $\begin{array}{l}\text { See text } \\
\text { See text } \\
\text { WHO publications: Improving Access to Quality }\end{array}$ \\
$\begin{array}{l}\text { Nare in Family Planning: Medical Eligibility } \\
\text { Criteria for Contraceptive Use (2000) and }\end{array}$ & $\begin{array}{l}\text { information } \\
\text { Celected Practice Recommendations for }\end{array}$ \\
$\begin{array}{l}\text { The Cochrane Library } \\
\text { MEDLINE and EMBASE from 1996 to 2004 }\end{array}$ & $\begin{array}{l}\text { No relevant } \\
\text { information }\end{array}$ \\
\end{tabular}

FFPRHC, Faculty of Family Planning and Reproductive Health Care; RCOG, Royal College of Obstetricians and Gynaecologists; WHO, World Health Organization. intrauterine device which is unaffected by liver enzymeinducers. ${ }^{8}$ The CEU recommended that for women using liver enzyme-inducers, two tablets (i.e. $1.5 \mathrm{mg}$ ) of levonorgestrel should be taken as soon as possible and within 72 hours of unprotected sex. This should be followed by one tablet $(0.75 \mathrm{mg})$ of levonorgestrel 12 hours later. This advice is supported by the Scottish Intercollegiate Guidelines Network in a Guideline on the diagnosis and management of epilepsy in adults, ${ }^{9}$ by advice in the current edition of the British National Formulary ${ }^{10}$ and Guidance from the Department of Health. ${ }^{11}$ This advice is, however, based on non-analytical studies, expert opinion and data extrapolated from higher quality studies. There are no data on the optimal dose and timing of POEC in women using liver enzyme-inducers.

MEDLINE and EMBASE. A large, randomised, controlled trial, conducted by the $\mathrm{WHO}^{12}$ found that a single $1.5 \mathrm{mg}$ dose of levonorgestrel was equivalent to the divided regimen of $0.75 \mathrm{mg}$ taken 12 hours apart in women not using liver enzyme-inducers. Although equivalence cannot be demonstrated with absolute certainty, these data from the WHO trial provided sufficient evidence to support a change to the product licence for Levonelle ${ }^{\circledR}$ and Levonelle- $2^{\circledR}$ (Schering Health Care). The Medicines and Healthcare products Regulatory Agency granted a change to the product licence in October 2003, which allows POEC to be given as a single $1.5 \mathrm{mg}$ dose in routine practice. ${ }^{13}$

Although the WHO data supported a single dose $(1.5 \mathrm{mg})$ of levonorgestrel in routine practice, no evidence was identified regarding the use of POEC by women taking liver enzyme-inducers. Currently there is no evidence to support a single regimen of three tablets (i.e. $2.25 \mathrm{mg}$ ) of levonorgestrel for women taking liver enzyme-inducers. Although this regimen may seem logical, there is no evidence to support it at this time or to predict the side effects, such as nausea or vomiting, which may occur. Until more evidence is available, the recommendation for POEC use by women taking liver enzyme-inducers has not changed.

\section{Disclaimer}

The advice given in this Member's Enquiry Response has been prepared by the FFPRHC Clinical Effectiveness Unit team. It is based on a structured search and review of published evidence available at the date of preparation. The advice given here should be considered as guidance only. Adherence to it will not ensure a successful outcome in every case and it may not include all acceptable methods of care aimed at the same results. This response has been prepared as a service to FFPRHC members, but is not an official Faculty Guidance product; Faculty Guidance is produced by a different and lengthier process. It is not intended to be construed or to serve as a standard of medical care. Such standards are determined on the basis of all clinical data available for an individual case and are subject to change as scientific knowledge advances. Members are welcome to reproduce this Response by photocopying or other means, in order to share the information with colleagues.

\section{Acknowledgement}

The CEU acknowledges the support provided by Mrs Tracey Chiverton, the CEU Secretary responsible for maintaining the CEU Members' Enquiry Database.

References

1 Faculty of Family Planning and Reproductive Health Care. FFPRHC Guidance (January 2004). The copper intrauterine device as longterm contraception. J Fam Plann Reprod Health Care 2004; 30(1): $29-42$.

2 de Souza A, Brechin S, Penney G. The members' enquiry service: frequently asked questions. J Fam Plann Reprod Health Care 2003; 29(4): 225-226.

3 World Health Organization (WHO). Selected Practice Recommendations for Contraceptive Use. Geneva, Switzerland: WHO, 2002.

4 de Souza A, Brechin S, Penney G. The member's enquiry service: frequently asked questions September 2001-August 2002 and an illustrative response. J Fam Plann Reprod Health Care 2003; 29(2): $45-47$. 
5 Faculty of Family Planning and Reproductive Health Care Clinical Effectiveness Unit. FFPRHC Guidance (April 2003). Emergency contraception. J Fam Plann Reprod Health Care 2003; 29(2): 9-16.

6 de Souza A, Brechin S, Penney G. The member's enquiry service: frequently asked questions. J Fam Plann Reprod Health Care 2003; 29(3): 160-161.

7 Faculty of Family Planning and Reproductive Health Care Clinical Effectiveness Unit. FFPRHC Guidance (July 2003). Contraceptive choices for women with inflammatory bowel disease. J Fam Plann Reprod Health Care 2003; 29(3): 127-134

8 Faculty of Family Planning and Reproductive Health Care (FFPRHC). FFPRHC Guidance (April 2000). Emergency contraception: recommendations for clinical practice. Br J Fam Plann 2000; 26: 93-96.

9 Scottish Intercollegiate Guidelines Network (SIGN). Diagnosis and
Management of Epilepsy in Adults: A National Clinical Guideline. Guideline No. 70. Edinburgh, UK: SIGN, April 2003.

10 British National Formulary, No. 46, September 2003. London: British Medical Association and the Royal Pharmaceutical Society of Great Britain, 2003. http://www.BNF.org

11 Department of Health. PRODIGY Guidance: Contraception emergency. London, UK: Department of Health, 2001. http://www.prodigy.nhs.uk

12 von Hertzen H, Piaggio G, Ding J, et al. Low dose mifepristone and two regimens of levonorgestrel for emergency contraception: a WHO multicentre randomised trial. Lancet 2002; 360: 1803-1810.

13 Schering Health Care Ltd. New dose instructions for Levonelle-2. 2003. Levonelle-Electronic Medicines Compendium. $\mathrm{http}: / / \mathrm{emc} . \mathrm{medicines}$.org.uk/emc/assets/c/html/displaydoc.asp?docu mentid $=4231$

\title{
SHORT COMMUNICATION
}

\section{The prevalence rates of domestic abuse in women attending a family planning clinic}

\author{
June Keeling, BSc, RGN, Domestic Violence Co-ordinator/Researcher; Linda Birch, BSc, MA, Senior Lecturer/Practitioner, \\ Duchess of Westminster Wing, Arrowe Park Hospital, Upton, UK
}

Correspondence: Mrs June Keeling, PDRU, Duchess of Westminster Wing, Arrowe Park Hospital, Arrowe Park Road, Upton, Wirral CH49 5PE, UK. E-mail: june.keeling@whnt.nhs.uk

(Accepted 27 November 2003)

Journal of Family Planning and Reproductive Health Care 2004; 30(2): 113-114

\begin{abstract}
Context Domestic abuse has a detrimental impact on the mental and physical health of a woman. The abusive partner may use physical and sexual violence and 'control' the choice of contraception.
\end{abstract}

Objective To examine the prevalence rates of domestic abuse.

Design Data collection using anonymous questionnaire.

Setting A family planning clinic.

Participants Two hundred and ninety-two women.

Main outcome measures The prevalence rate of past and present history of domestic abuse and the nature of the abuse.

Results One in three women experienced domestic abuse at some time in their life. A significant relationship existed between the age of the woman and experiencing abuse within the last year. Women in full-time employment experienced the highest rates of abuse.

Discussion The anonymity of the research and the method of implementation encouraged an excellent response rate. Conclusion During a woman's childbearing years, onethird of women may experience domestic abuse from their partner.

\section{Introduction}

Domestic abuse can be defined as 'any violence between current or former partners in an intimate relationship, wherever and whenever the violence occurs'. The violence can include physical, sexual, emotional or financial abuse. $^{1}$ Sexual violence includes forced anal, oral and vaginal sex and enforced prostitution, which may result in sexual dysfunction. ${ }^{2}$ The abusive partner may also control the woman's choice of contraceptive method. A recent study identified that $26.2 \%$ of women had experienced partner control over the choice of family planning methods. ${ }^{3}$

The aim of this research was to identify the prevalence rate of domestic abuse experienced by women accessing a family planning clinic (FPC).

\section{Method}

The Wirral Ethics Committee granted ethical approval and the research commenced in May 2002. All women attending the FPC at the district general hospital were invited to participate. There were no exclusions. Any accompanying partner (male or female) was surreptitiously removed to ensure the woman's and the researcher's safety. Following verbal consent, a self-administered questionnaire was completed in private to ensure a noncoercive response.

Quantitative data collection was achieved using an anonymous self-administered questionnaire, the Abuse Assessment Screen (AAS). ${ }^{4}$ The Nursing Research Consortium on Violence and Abuse developed the AAS. It uses five closed questions to assess past and recent history of abuse and the nature of the abuse. The reliability of the AAS has been demonstrated to be equivalent to the Conflict Tactic Scale. ${ }^{5}$ The AAS was supplemented to enable the collection of demographic data. The right to refuse was upheld and women were assured that this would not alter the care they received. The number of refusals was recorded.

Table 1 Prevalence of domestic abuse by age group

\begin{tabular}{lrlr}
\hline $\begin{array}{l}\text { Age range } \\
\text { years) }\end{array}$ & $\begin{array}{l}\text { Completed } \\
\text { questionnaires } \\
\text { (n) } \% \text { of total) }\end{array}$ & $\begin{array}{l}\text { Women reporting } \\
\text { domestic abuse at } \\
\text { some stage in their } \\
\text { life (n) } \% \text { of each } \\
\text { age group) }\end{array}$ & $\begin{array}{l}\text { Women reporting } \\
\text { domestic abuse in } \\
\text { the last } 12 \text { months } \\
\text { (n) } \% \text { of each } \\
\text { age group) }\end{array}$ \\
\hline $16-24$ & $105(36.0)$ & $34(32.4)$ & $24(22.9)$ \\
$25-29$ & $46(15.8)$ & $14(30.4)$ & $3(6.5)$ \\
$30-34$ & $47(16.1)$ & $18(38.3)$ & $3(6.4)$ \\
$35-39$ & $42(14.4)$ & $19(45.2)$ & $6(14.3)$ \\
$40-44$ & $25(8.6)$ & $6(24.0)$ & 1 \\
$45-49$ & $9(3.1)$ & $5(55.6)$ & $1(11.1)$ \\
$\geq 50$ & $11(3.8)$ & $2(18.2)$ & 1 \\
Missing data & $7(2.4)$ & $4(57.1)$ & $2(28.1)$ \\
Totals & $292(100)$ & $102(34.9)$ & $41(14.0)$ \\
\hline
\end{tabular}

